\title{
Research on Two-stage Game Strategy of Virtual Power Plant in Deep Peak Regulation Auxiliary Service Market
}

\author{
Yuan Guili ${ }^{1}$, Chen Sixuan ${ }^{1 *}$, Dou Xiaoxuan ${ }^{1}$ \\ ${ }^{1}$ Control and Computer Engineering School, North China Electric Power University, Beijing, China
}

\begin{abstract}
There is a large number of combined heat and power units in northern China, and due to the limit of heating demand, the operating mode of setting electricity by heat of combined heat and power units has seriously took over the consumption space of other energy, resulting in severe wind power curtailment and rationing situation in some areas, so this paper studies the deep peak regulation bidding strategy problem considering multiple uncertainties on virtual power plants, and established a two-staged optimization model of virtual power plant to maximize the net revenue, then introduced the Shapely value method with correction coefficient redistribute the peak regulation revenue. The simulation results showed that the two-stage bidding model can not only improve the market competitiveness of the virtual power plant, but also promote the consumption of renewable energy and reduce the market peak regulation service cost. Meanwhile, the improved apportion method can effectively guarantee the enthusiasm of all kinds of units to participate in the deep peak regulation market.
\end{abstract}

\section{Introduction}

In the energy installed structure of northern China, combined heat and power (CHP) unit accounted for about half of the total installed units, but CHP units lack of flexibility, especially in the heating period, a large number of pure condensing thermal units are forced to stop running, limited by users' thermal load, CHP units' electrical output adjustment space is confined, which leads to shortages in peak regulation resources in system. Therefore, encouraging CHP units to make full use of all kinds of flexible resources and methods, and actively participate in the peak regulation of power grid are the key to increase the consumption of renewable energy in the "three north" region. In 2016,according to the instructions of the National Energy Administration, Northeast Energy Regulatory Administration issued the Pilot Program for Special Reform of Northeast Electric Power Auxiliary Service Market and the Operating Rules of Northeast Electric Power Auxiliary Service Market (Trial). ${ }^{[1]}$, then the electric power auxiliary service market has been established in Northeast China, aiming to ease the contradiction between heat and electricity in this region and promote the consumption of renewable energy in Northeast China. However, according to statistics, in 2019, the peak adjustment compensation cost of the auxiliary service power market in Northeast China has reached 3.642 billion yuan ${ }^{[2]}$.The research on bidding strategy of deep peak regulation for thermal power units can effectively improve the market vitality, reduce the compensation cost of peak regulation market, and further promote the development and perfection of ancillary service market mechanism.

As for the auxiliary service market of deep peak regulation, most of the relevant literature focuses on how the pure condensing thermal power units participate in the peak regulation market to obtain the maximum benefit of peak regulation ${ }^{[3-5]}$, or how to allocate the benefit of peak regulation. However, the issue of the participation of CHP units in the deep peak regulation market(DPRM) has only been studied recently. For example, Literature [6] proposed the layered call sequence and strategy of pumped-storage hydroelectric plant and thermal power units, and established the layered optimal dispatching model of joint peak load regulation. Literature [7] studied the problem of considering the price-based demand response and thermal power plants with energy storage equipment to assist thermal power units to participate in the auxiliary service of peak regulation, and established an optimal dispatching model considering the initiative of thermal power depth peak regulation to achieve the goal of optimizing the system economy and minimize the wind abandonment rate. Literature [8] built a thermal power peak regulation model considering the low load fatigue life loss and oil injection cost by utilizing multiple types of resources composed of thermal power units, demand response and energy storage, and proposed a power system flexibility margin index including source-loadstorage flexible resources to evaluate the contribution of various flexible providers to system flexibility. Most of the literatures only studied the problem of peak regulation of pure condensing thermal power units in cooperation with other units, and literatures about CHP units in peak regulation mainly focused on the compensation price of $\mathrm{CHP}$ and the problem of how to use other resources to

"Corresponding author's e-mail: 1182227024@ncepu.edu.cn 
provide more peak regulation quantity ${ }^{[9,10]}$, such as Literature [11] studied the compensation price of paid peak regulation and the optimal strategy of the distribution of peak regulation benefits within the energy system, so as to motivate cogeneration units to make full use of heat storage devices and auxiliary heat sources to improve the flexibility of power system. Literature [12] studied the problem of the optimal capacity of electric boilers when CHP units participating in peak regulation market, and simulation model calculated the optimal capacity of electric boilers established with the goal of unit peak load regulation increment and economic net present value under characteristic days.

All the literatures didn't deal with the bidding strategy of CHP and thermal power units participating in the electricity market and the deep peak regulation market ${ }^{[13]}$, And most studies only consider the uncertainty of the marginal clearing price of the market ${ }^{[14,16]}$, There is basically no discussion on the bidding strategy while considering multiple uncertainties of competitor's bidding decision and load, wind tuebine, and the characteristics of different units are not fully considered into the income distribution of thermal power plants, which is not reasonable for small units with low peak load capacity.

For the above problems, this paper studied the bidding strategy in deep peak regulating of virtual power plant (VPP) considering various uncertainties. First stage, using the Latin hypercube sampling(LHS) method $^{[16]}$ to generate user load and wind turbine output scenarios to describe the uncertainties of them, and in the case of electrical and thermal demand are satisfied, minimizing the overall operating cost to get the expected bidding quantity of each VPP, and considering that the strategy players need to deal with the uncertainty of the competitor's quotation and bidding amount, LHS method is also adopted to generate the scenario set of the competitor's quotation strategy, and the optimal quotation coefficients of different strategy players are obtained through pre-clearance, then using the queuing method to solve the peak market clearance model and get the winning electricity and market marginal clearing price with the objective function of lowest cost of peak regulation. The second stage, scheduling with the goal of maximizing the virtual power plant total revenue and determine its actual power generation project, then introducing load deviation compensation fees to ensure bidding quantity of each market still can be satisfied after internal adjustment of VPP, and by adding the coefficient of Shapley value method which considering load historical contribution and peak regulation realization degree to correct the profit apportioned, so that various units keep enthusiasm in peak regulating market, then renewable energy consumption can get improved.

\section{Deep-peak market trading rules and uncertainty modeling}

Deep peak regulation market in Northeast China divides a day into 96 periods, and each trading period is 15 minutes. In this paper, a cycle starts at 0:00. In the preclearing stage, each VPP obtains its own bidding strategy, and reports the next day's deep peak regulation quotation and quantity to the market dispatching agency. In the intraday stage, when there is demand for peak regulation, the dispatching center will follow the principle of "call on demand and call in order" and the order the bidding of VPPs, to dispatch from the lowest bidding price to the highest bidding price until the demand for peak regulation is satisfied.

The bidding quotation of VPP in the DPRM needs to be determined by taking the forecast load demand, wind power output and the situation of competitors into account. First VPPs need to determine the peak regulating amount that may take part in peak regulating ancillary services, therefore, the uncertainties of load demand and wind power output have a great influence on the bidding results of VPPs, secondly VPPs need to consider its competitors' bidding strategies before making its bidding strategies so as to obtain the maximum peak-shifting benefits, so it is necessary to optimize VPP's bidding strategies under different game behaviors of competitors, this paper uses the LHS method to generate multiple scenarios to describe the uncertainties of the above three. The thermal load is usually calculated by the predicted value of temperature, and the predicted result of temperature is relatively accurate. In addition, the thermal comfort ${ }^{[17]}$ is considered in this paper, so the uncertainty of thermal load prediction is temporarily not considered.

\section{The virtual power plant participates in the two-stage bidding model of peak regulation auxiliary service}

\subsection{The pre-clearance model of deep peak regulation}

The first stage is mainly to obtain the time and expected peak regulating amount of VPPs participating in the DPRM, and obtain the best quotation coefficient for each VPP. Therefore, in this optimization model, only the constraints of safe operation of the generator units and the constraints of electrical and thermal balance are considered.

\subsubsection{Expected peak regulating amount model}

The peak regulating amount is calculated with the goal of the lowest power generation cost of VPPs, and the objective function is expressed as (1):

$$
\begin{gathered}
\min f_{v}=\sum_{i=1}^{k}\left(a_{i, 0}+a_{i, t} p_{i, t}^{c}+a_{i, 2} h_{i, t}+a_{i, 3}\left(p_{i, t}^{c}\right)^{2}+a_{i, 4} p_{i, t}^{c} h_{i, t}+a_{i, 5} h_{i, t}^{2}\right)+\sum_{j=1}^{t}\left(c_{j, 0}+c_{j, 1} p_{j, t}^{f}+c_{j, 2}\left(p_{j, t}^{f}\right)^{2}\right) \\
\sum_{i=1}^{k} p_{i, t}^{c}+\sum_{i=1}^{k} p_{i, t}^{f}=E_{s, t}-p_{s, w} \\
p_{i, \min }^{c} \leq p_{i, t}^{c} \leq p_{i, \max }^{c} \\
p_{j, \min }^{f} \leq p_{j, t}^{f} \leq p_{j, \max }^{f}
\end{gathered}
$$




$$
\begin{gathered}
L_{s, t}^{\min } \leq \sum_{i=1}^{k} h_{i, t} \leq L_{s, t}^{\max } \\
0 \leq h_{i, t} \leq h_{i, \max } \\
p_{i, d}^{c} \leq p_{i, t}^{c} \leq p_{i, u}^{c} \\
p_{j, d}^{f} \leq p_{j, t}^{f} \leq p_{j, u}^{f} \\
\max \left\{p_{i, \text { min }}^{c}-c_{i, v} h_{i, t}, p_{i, \text { mid }}^{c}+c_{i, m} h_{i, t}\right\} \leq p_{i, t}^{c} \leq p_{i, \max }^{c}-c_{i, v} h_{i, t}
\end{gathered}
$$

$\mathrm{s}$ is the number of scenarios, ${ }^{i, v}, c_{i, m}$ respectively are different operating state parameters of CHPs, $a_{i, 0} \sim a_{i, 5}$ and $c_{i, 0} \sim a_{i, 2}$ are the coal consumption parameter of CHPs and pure condensing thermal power units, $h_{i, t}$ and $p_{i, t}^{c}$ are respectively the thermal output and electrical output of CHP unit at time $\mathrm{t}, p_{j, t}^{f}$ is the electrical output of the pure condensing thermal power unit at the time $\mathrm{t}$, $p_{i, \text { max }}^{c}, p_{i, \text { min }}^{c}$ and $p_{j, \text { max }}^{f}, p_{j, \text { min }}^{f}$ are the upper and lower limits of the power outputs of CHP and thermal power units, $p_{i, u}^{c}, p_{i, d}^{c}$ and $p_{j, u}^{f}, p_{j, d}^{f}$ are the upper and lower limits of climbing for CHP and thermal power units, $h_{i, \max }$ are the maximum heat output of the CHP unit, $E_{s, t}$ is predicted electrical load demand at time t, $p_{s, w}$ is predicted wind power output at time $\mathrm{t}, L_{s, t}^{\max }$ and $L_{s, t}^{\min }$ are the upper and lower limits of heating demand within the comfort range, and can be calculated by formula(10$11)$.

$$
\begin{gathered}
P M V=2.43-\frac{3.76\left(t_{s}-t_{a}\right)}{M\left(I_{c l}+0.1\right)} \\
H_{v p p}=\frac{\gamma A\left(T_{\text {in }}-T_{\text {out }}\right)}{T_{\text {inc }}-T_{\text {outc }}}
\end{gathered}
$$

$H_{v p p}$ is the predicted heat demand, $P M V$ is the comfort level, $t_{s}$ and $t_{a}$ represent human surface temperature and ambient air temperature respectively, and $t_{s}$ can be set as 33.5 according to Fanger research, $M$, energy metabolic rate, is $70 \mathrm{~W} / \mathrm{m}^{2}$, the clothing thermal resistance $I_{c l}$ is $0.2\left(\mathrm{~m}^{2} \cdot{ }^{\circ} \mathrm{C}\right) / \mathrm{W}, \mathrm{A}$ is district heating area, $T_{\text {inc }}$ and $T_{\text {outc }}$ represent indoor and outdoor standard temperatures respectively, $T_{\text {in }}$ and $T_{\text {out }}$ are indoor and outdoor real-time temperature, $\gamma$ is regional heating index ${ }^{[20]}$.

Table (1) is relevant provisions of the northeast China peak regulation auxiliary service. market about the thermal power units participating in the DPRM:

Table 1. Stipulates about thermal power units in peak regulation market

\begin{tabular}{|c|c|c|c|c|}
\hline $\begin{array}{c}\text { Offer } \\
\text { gear }\end{array}$ & Unit type & $\begin{array}{c}\text { Loading rate of thermal } \\
\text { power plant }\end{array}$ & $\begin{array}{c}\text { Price ceiling } \\
(\text { yuan/KWh) }\end{array}$ & $\begin{array}{c}\text { Price lower limit } \\
\text { (yuan/KWh })\end{array}$ \\
\hline $\begin{array}{c}1^{\text {st }} \\
\text { gear }\end{array}$ & $\begin{array}{c}\text { CHP unit } \\
\text { pure condensing } \\
\text { thermal power unit }\end{array}$ & $40 \%<$ load rate $\leq 50 \%$ & 0.4 & 0 \\
\hline $\begin{array}{c}2^{\text {nd }} \\
\text { gear }\end{array}$ & $\begin{array}{c}\text { all thermal power } \\
\text { unit }\end{array}$ & load rate $\leq 40 \%$ & 1 & 0.4 \\
\hline
\end{tabular}

After unit retrofitted, the average load rate of CHP units and thermal power units can be reduced to less than $40 \%$. However, the average load rate of CHP units and pure condensing thermal power units presented in this paper can be calculated from the expected peak regulating amount model above, which are more than $40 \%$, so VPPs can only participate in the quotation of the first gear.

According to the expected peak regulating amount model, the time and the output of each VPP participating in the DPRM were obtained, when the output of VPPs' unit is at the first load rate requirement, $\varpi(s, t)$ is 1 , indicating that the VPP can participate in the DPRM, or else $\varpi(s, t)$ is 0 , indicating that VPP doesn't participate in the DPRM.

$$
\varpi(s, t)=\left\{\begin{array}{l}
0, p_{i, s}^{c}\left(p_{i, s}^{f}\right)>50 \% p_{i, \text { max }}^{c}\left(48 \% p_{i, \text { max }}^{f}\right) \\
1,40 \% p_{i, \text { max }}^{c}\left(40 \% p_{i, \text { max }}^{f}\right)<p_{i, s}^{c}\left(p_{i, s}^{f}\right) \leq 50 \% p_{i, \text { max }}^{c}\left(48 \% p_{i, \text { max }}^{f}\right)
\end{array}\right.
$$

\subsubsection{Optimal bidding model of deep peak regulation market}

Assumed that the quoted price and bidding electricity of all VPP participating in the DPRM obey a linear relationship, as shown in equation (11), where $p_{i}$ is expected peak regulating amount, $b_{i}$ and $d_{i}$ are quotation factor, $\lambda_{i}$ is the bidding price.

$$
\lambda_{i}\left(p_{i}\right)=b_{i} p_{i}+d_{i}
$$

In addition to its own operation and maintenance costs and corresponding constraints, VPP also needs to consider other competitors' possible quotations when setting its own quotation, in this paper, assuming that strategy subject i mastered the part of the history information of its rival bidding information and the peak regulating market, so other competitors quotation coefficient can be estimated. For VPP i, competitor j's bidding coefficient are two-dimensional gaussian distribution, the probability 
density function is as follows:

$$
\left(b_{i j}, d_{i j}\right) \sim N\left(\left[\begin{array}{l}
u_{b, i j} \\
u_{d, i j}
\end{array}\right],\left[\begin{array}{cc}
\varphi_{b, i j}^{2} & \xi_{i j} \varphi_{b, i j} \varphi_{d, i j} \\
\xi_{i j} \varphi_{b, i j} \varphi_{d, i j} & \varphi_{d, i j}^{2}
\end{array}\right]\right)
$$

$b_{i j}, d_{i j}$ respectively represent the estimated value of the quotation coefficient of competitor $\mathrm{j}$ to strategy subject i. ${ }_{b, i j}, u_{b, i j}$ are the mean estimates of the coefficients $b_{i}, d_{i}, \varphi_{b, i j}, \varphi_{d, i j}$ represent the standard deviation estimate of the coefficient $b_{i}, d_{i}, \quad \xi_{i j}$ is coefficient of correlation of $b_{i}, d_{i}, \xi_{i j}$ is -1 which the purpose is increasing one of $b_{i}, d_{i}$ and lowering the other to gain more winning power. In order to get the best bidding strategy for VPP, it is also necessary to obtain the peak adjustment time and peak demand. The peak demand can be predicted from the historical data, then time of peak regulation are as follows:

$$
\tau(t)= \begin{cases}0 & , p_{t}^{m s p}=0 \\ 1 & , p_{t}^{m s p}>0\end{cases}
$$

$p_{t}^{m s p}$ is predicted peak demand, when the demand is greater than $0, \tau(t)$ is 1 , the market needs peak regulation auxiliary service, when the demand is equal to $0, \tau(t)$ is 0 , the market doesn't need peak regulation auxiliary service.

After VPP i predicted the competitor's bidding coefficient and the deep peak demand, the optimal bidding strategy is determined with the goal of maximizing the peak regulation revenue, The physical operating constraints are consistent with the expected peak regulating amount model and will not be described here.

$$
\begin{gathered}
\max E_{f}(i)=\sum \tau(s, t) \operatorname{pro}(s) \sum_{k=1}^{r} \varpi(s, t)\left(\lambda_{t, k}^{m c p} p_{i}^{b i d}-f_{s, s p}\right) \\
\text { s.t } \sum_{i \in N} p_{i}^{b i d}=p_{s}^{m}
\end{gathered}
$$

As shown in the above formulas, $p_{i, s}^{s t}$ is VPP's expected peak regulating amount under scene s, $\lambda_{t, k}^{m c p}$ is the marginal clearing price under the current bidding strategy, $p_{i}^{\text {bid }}$ is the bidding amount of VPP, pro is the probability of the predicted deep peak demand scene, $p_{s}^{m}$ is the predicted market peak demand.

$f_{s, s p}$ is the unit wear cost of thermal power unit in deep peak regulation, when the thermal power unit output is less than the minimum technical output, there is a abrasion to the equipment, which including the loss produced by rotor metal subjected to alternating stress, and creep losses due to high temperature and sustained load forces, here Manson-Coffin formula is used to calculate the unit wear cost, as shown in formula (18), $\beta$ is the loss coefficient of the actual operating depth of the thermal power unit, $C_{u n i t}$ is the investment cost of unit i, $N_{f, i, t}$ is the cycle number of the rotor cracking of the thermal power unit at time $t$, its value is related to the declared output $p_{f, i, t}$ of unit $\mathrm{i}$ at time $\mathrm{t}$.

$$
f_{s, s p}=\sum \frac{\beta C_{i, u n i t}}{2 N_{f, i, t}}
$$

After all VPPs which decided to participate in the peak regulation market have determined the optimal quotation strategy and reported it to the market center, the peak regulation market center will clear the market with the aim of minimizing the cost of purchasing the peak regulation service. The objective function is shown in formula(19):

$$
\begin{gathered}
\min F_{s p}=\sum_{t=1}^{T} \sum_{i=1}^{N} \tau(t) c_{t}^{b i d} p_{i, t}^{b i d} \\
\text { s.t } \sum_{i \in N} p_{i, t}^{b i d}=p_{t}^{m} \\
0 \leq p_{i, t}^{b i d} \leq 50 \%(48 \%)\left(p_{i, \max }-p_{i, s}^{c}\left(p_{i, s}^{f}\right)\right) \\
p_{i, d} \leq p_{i, t}^{b i d}-q_{i, t-1}^{b i d} \leq p_{i, u}
\end{gathered}
$$

$F_{s p}$ is the cost of the market center for purchasing peak regulation service, $c_{t}^{\text {bid }}$ is the actual marginal clearing price, $p_{i, t}^{b i d}$ is the winning electricity quantity of VPP at time $\mathrm{t}, p_{t}^{m}$ is the actual demand of the peak regulation market, $p_{i, \text { max }}$ is the maximum technical output of VPP, $p_{i, d}$ and $p_{i, u}$ is the maximum and minimum climbing rate limit.

\subsection{The second stage scheduling model}

\subsubsection{Object function}

According to the results obtained in the first stage, the second-stage model conducts scheduling with the goal of maximizing the net revenue, the objective function is shown in equation (23), $B_{s, s p}, \quad B_{s, e}$ and $B_{s, h}$ are respectively the revenues of peak regulation, electricity sale and heat sale, $f_{s, v}, f_{s, s p}$ and $f_{s, d i v}$ are respectively the cost of actual coal consumption, deep peak regulation and peak regulation deviation.

$$
\max \sum_{c=1}^{s} \rho_{s}\left(B_{s, s p}+B_{s, e}+B_{s, h}-f_{s, v}-f_{s, s p}-f_{s, d i v}\right)
$$

The revenue of deep peak regulation is shown in equation (24), which can be obtained from the first stage model:

$$
B_{s, s p}=c_{t}^{b i d} p_{i, t}^{b i d}
$$

Revenue of electricity sale is shown in formula (25), $\lambda_{g}$ is the time-of-use electricity price of power grid, $\omega_{i}$ is deviation penalty factor, $p_{i, s}^{c}$ and $p_{j, s}^{f}$ are the electricity outputs of CHP and thermal power units in first stage 
model, $p_{i, s}^{c, t}$ and $p_{j, s}^{f, t}$ are the actual outputs of them during the internal optimization dispatching

$$
B_{s, e}=\lambda_{g}\left(\sum_{i=1}^{k} p_{i, s}^{c}+\sum_{j=1}^{l} p_{j, s}^{f}\right)-\omega_{i} \lambda_{g}\left|\left(\sum_{i=1}^{k} p_{i, s}^{c}+\sum_{j=1}^{l} p_{j, s}^{f}\right)-\left(\sum_{i=1}^{k} p_{i, s}^{c, t}+\sum_{j=1}^{l} p_{j, s}^{f, t}\right)\right|
$$

In formula (26). $\lambda_{h}$ is the price of heat sale, $h_{s, \max }$ and $h_{s, \text { min }}$ are the upper and lower limits of users' thermal demand.

$$
B_{s, h}=\lambda_{h} \sum_{i=1}^{k} h_{s, i}-\left\{\begin{array}{l}
\omega_{i} \lambda_{h}\left|\sum_{i=1}^{k} h_{s, i}-h_{s, \max }\right|, h_{s, i}>h_{s, \max } \\
\omega_{i} \lambda_{h}\left|\sum_{i=1}^{k} h_{s, i}-h_{s, \min }\right|, h_{s, i}<h_{s, \min }
\end{array}\right.
$$

$f_{s, d i v}$ is the peak regulation deviation cost. The linear constraint proposed in reference [18] represents the cost, $\alpha_{t}^{u}$ and $\alpha_{t}^{d}$ are the peak regulation service cost coefficient when VPP exceeds the upper limit and the lower limit.

$$
\left\{\begin{array}{l}
f_{s, d i v} \geq \alpha_{t}^{u}\left(\left(\sum_{i=1}^{k} p_{i, s}^{c}+\sum_{j=1}^{l} p_{j, s}^{f}\right)-\left(\sum_{i=1}^{k} p_{i, s}^{c, t}+\sum_{j=1}^{l} p_{j, s}^{f, t}\right)\right) \\
f_{s, d i v} \geq \alpha_{t}^{d}\left(\left(\sum_{i=1}^{k} p_{i, s}^{c}+\sum_{j=1}^{l} p_{j, s}^{f}\right)-\left(\sum_{i=1}^{k} p_{i, s}^{c, t}+\sum_{j=1}^{l} p_{j, s}^{f, t}\right)\right) \\
f_{s, d i v} \geq 0
\end{array}\right.
$$

\subsubsection{Improved Shapley apportionment method}

At present, Shapley value method, as the most basic and effective method to study the reasonable sharing of common interests, has been widely applied. The specific expression is:

$$
\gamma_{i}(v)=\sum_{J \in N, i \notin j} \frac{(j) !(n-j-1) !}{n !}(v(J)-v(J \backslash i))
$$

$\gamma_{i}(v)$ is the profit obtained of unit $\mathrm{i}$ after apportionment; $\mathrm{N}$ represents all units in VPP, $\mathrm{n}$ is the number of units which participating in the peak regulation market, $\mathrm{J}$ is all alliance sets excluding unit $\mathrm{i}, \mathrm{j}$ is the number of alliance $\mathrm{J}, v(J)$ is all alliances benefits that include member $\mathrm{i}, v(J \backslash i)$ is all alliances benefits that not include member $\mathrm{i}$.

Shapley apportionment method mainly considers the marginal contribution of the participants to the revenue of the alliance, so after participating in peak regulation market, VPP with larger capacity and stronger peak regulation ability can distribute higher returns, however high coal consumption quantity of small capacity units 's peak regulating enthusiasm is higher, thus this paper established improved Shapley apportionment method considering peaking realized degree and the historical contributions, to incentive units contribute more peak adjustment and improve the fairness of distribution mechanism

Then the new allocation weight of unit $\mathrm{i}$ in VPP is as formula(29), $\kappa$ is historical contribution weight, $q_{i}$ is all peak regulation quantity of unit $i$ in historical period, $q_{\text {total }}$ is total peak regulation quantity of VPP, $\alpha_{i}$ is the realization coefficient of peak regulation ability, $\pi_{i}$ is the ratio of the actual peak adjustment of unit $i$ to the maximum adjustable peak amount, $p_{i, d \text { max }}$ is the maximum adjustable peak regulation amount of unit $\mathrm{i}$, $p_{i, r s p}$ is the actual peak regulation amount of the unit $\mathrm{i}$.

$$
\begin{gathered}
R_{i}=\kappa \frac{q_{i}}{q_{\text {total }}}+(1-\kappa) \alpha_{i} \\
\alpha_{i}=\frac{\pi_{i}}{\sum_{i \in N} \pi_{i}} \\
\pi_{i}=\frac{p_{i, r s p}}{p_{i, d \max }}
\end{gathered}
$$

\section{Model data and simulation analysis}

\subsection{Model data}

In order to verify the validity of the two-stage optimization model, this paper studies the game model with VPP A, B and C as the main strategies subjects. It is assumed that there are $b=375.24$ and $d=0.326$ for VPP A, and $b=373.45$ and $d=0.313$ for VPP $B$, and $b=371.56$ and $\mathrm{d}=0.304$ for VPP C.

VPP's heat energy sale price is 90 (yuan/MWh), standard coal price is 500 (yuan/t), peak adjustment deviation compensation cost is 48 (yuan/MWh), the actual operating loss coefficient of thermal power plant is 1.2 , the invest cost of thermal power unit is 3464 yuan $/ \mathrm{kW}$, electrical and heating output deviation penalty factor is 1.2 .

Relevant parameters ${ }^{[15,19]}$ of units in VPP are shown in table (2):

Table 2. Operating parameters of thermal power units

\begin{tabular}{|c|c|c|c|c|}
\hline VPP & $\begin{array}{c}p_{i, \max } \\
(\mathrm{MW})\end{array}$ & $\begin{array}{c}p_{i, \min } \\
(\mathrm{MW})\end{array}$ & $\begin{array}{c}h_{i, \max } \\
(\mathrm{MW})\end{array}$ & $\begin{array}{c}\text { climbing } \\
\text { ability } \\
(\mathrm{MW})\end{array}$ \\
\hline \multirow{2}{*}{$\mathrm{A}$} & 330 & 148 & 365 & 90 \\
\cline { 2 - 5 } & 200 & 87 & 213 & 50 \\
\hline \multirow{2}{*}{$\mathrm{B}$} & 200 & 90 & - & 60 \\
\cline { 2 - 5 } & 300 & 120 & - & 100 \\
\hline $\mathrm{C}$ & 220 & 99 & - & 65 \\
\cline { 2 - 5 } & 220 & 100 & 260 & 50 \\
\hline
\end{tabular}




\subsection{Simulation analysis}

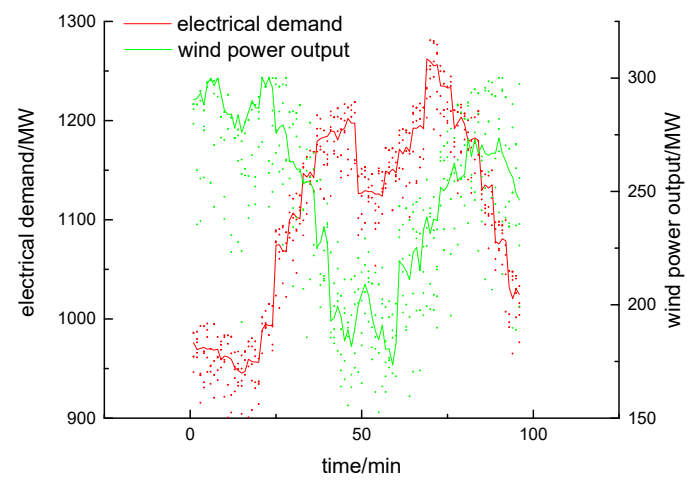

Electrical demand and wind power output scenarios are predicted by LHS method and are shown in figure 1.

According to the first stage model, VPP determined the quotation coefficient with the goal of maximum peak regulation revenue, and table 3 is the quotation coefficient of VPP A.

Figure 1. Forecast scene of electrical demand and wind power output

Table 3. Quotation coefficient of VPP A

\begin{tabular}{|c|c|c|c|c|c|}
\hline $\begin{array}{c}\text { Peek } \\
\text { regulation } \\
\text { time }\end{array}$ & $b_{i}$ (yuan/MW) & $\begin{array}{c}d_{i} \\
(\text { yuan/MW) }\end{array}$ & $\begin{array}{c}\text { Peek } \\
\text { regulation } \\
\text { time }\end{array}$ & $b_{i}$ (yuan/MW) & $\begin{array}{c}d_{i} \\
\text { (yuan/MW) }\end{array}$ \\
\hline 1 & 0.324 & 365.2846 & 13 & 0.3317 & 365.3597 \\
\hline 2 & 0.3203 & 365.3411 & 14 & 0.3170 & 365.3428 \\
\hline 3 & 0.3297 & 365.3338 & 15 & 0.3169 & 365.1893 \\
\hline 4 & 0.3179 & 365.4401 & 16 & 0.3221 & 365.3784 \\
\hline 5 & 0.3170 & 365.2559 & 17 & 0.3347 & 365.4347 \\
\hline 6 & 0.3222 & 365.3071 & 18 & 0.3246 & 365.374 \\
\hline 7 & 0.3357 & 365.3207 & 19 & 0.3359 & 366.5486 \\
\hline 8 & 0.3174 & 365.2607 & 20 & 0.3166 & 368.1925 \\
\hline 9 & 0.3281 & 365.3792 & 21 & 0.3180 & 367.4348 \\
\hline 10 & 0.3166 & 365.2474 & 22 & 0.3193 & 365.5055 \\
\hline 11 & - & - & 23 & 0.3337 & 367.1517 \\
\hline 12 & 0.3199 & 365.2597 & 24 & 0.3218 & 365.3928 \\
\hline
\end{tabular}

In this table, time 1 to 24 means 0:00 to 6:00. At this period, the user's electricity load demand is low, while the wind power output is high, however demand for heating is large, even the units run with the minimum technical output state, wind power output cannot be fully used, system's free peak regulation resources are insufficient, so in this period, "wind and heat conflict" phenomenon is relatively serious.

After the market center obtains the quotation strategy of each VPP, the clearing price under a certain scenario with the goal of minimizing the peak regulation cost is shown in the table 5:

Table 4. Peak market clearance price

\begin{tabular}{|c|c|c|c|c|c|}
\hline $\begin{array}{c}\text { Peek regulation } \\
\text { time }\end{array}$ & $\begin{array}{c}\text { clearance price } \\
\text { (yuan/MW) }\end{array}$ & $\begin{array}{c}\text { Peek regulation } \\
\text { time }\end{array}$ & $\begin{array}{c}\text { clearance price } \\
\text { (yuan/MW) }\end{array}$ & $\begin{array}{c}\text { Peek regulation } \\
\text { time }\end{array}$ & $\begin{array}{c}\text { clearance price } \\
\text { (yuan/MW) }\end{array}$ \\
\hline 1 & 372.0766 & 9 & 370.4398 & 17 & 364.8312 \\
\hline 2 & 365.3132 & 10 & 365.7798 & 18 & 370.6462 \\
\hline 3 & 365.7820 & 11 & 364.9211 & 19 & 367.6599 \\
\hline 4 & 369.3801 & 12 & 366.1676 & 20 & 369.2653 \\
\hline 5 & 366.7592 & 13 & 372.2326 & 21 & 363.7416 \\
\hline
\end{tabular}




\begin{tabular}{|l|l|l|l|l|l|}
\hline 6 & 365.0107 & 14 & 364.4353 & 22 & 365.0545 \\
\hline 7 & 368.3248 & 15 & 366.8076 & 23 & 372.7137 \\
\hline 8 & 366.4039 & 16 & 369.4281 & 24 & 364.4326 \\
\hline
\end{tabular}

In this scenario, the expected bidding quantity and actual bidding quantity of VPP A are shown in figure (2). In time 11, since the outputs of units in VPP A are higher than the paid peak regulation line, so VPP A doesn't participate in the bidding at this time. Figure (3) shows the peak regulation benefits of VPP A before and after adopting the optimized strategy. By adopting the optimal bidding strategy after predicting the bidding scenarios of competitors, the winning electrical quantity of VPP A is more than that without adopting the optimized strategy, and the peak regulation benefits are also better.

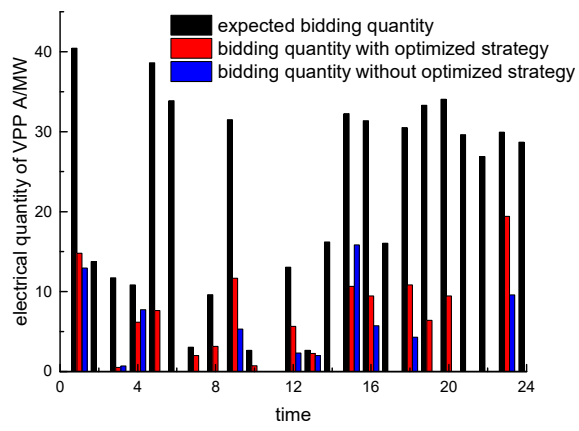

Figure 2. Winning bidding quantity of VPP A

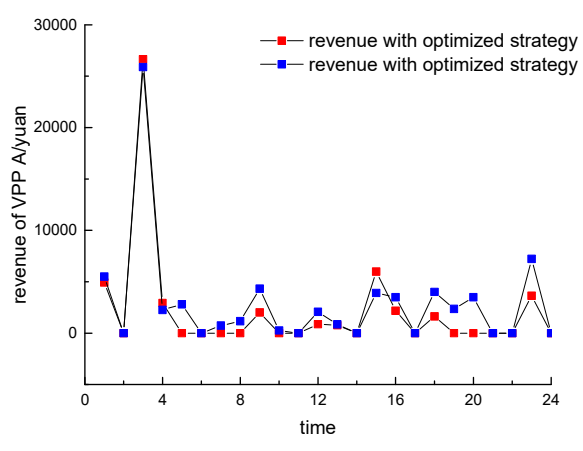

Figure 3. Winning bidding revenue of VPP A

As shown in figure (4), when all VPPs adopted optimized strategy proposed in this paper, due to CHP needs to meet the user's minimum heat supply in the expected peak regulation model, Therefore, the electricity output of CHP unit is relatively high after dispatching, The peak adjustment space of VPP with CHP is smaller, so VPP B and VPP C with pure condensing thermal power units have more winning bidding quantity in peak regulation.

As shown in figure (5), when all VPP automatically optimizes its own quotation in order to obtain higher peak regulation income, the cost of market clearing reduces by more than 6000 .

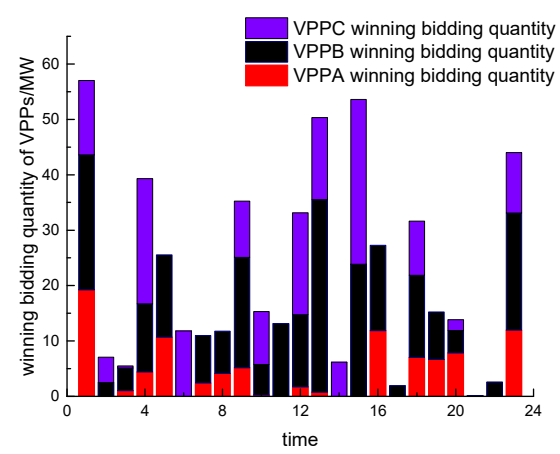

Figure 4. Winning bidding quantity of VPPs

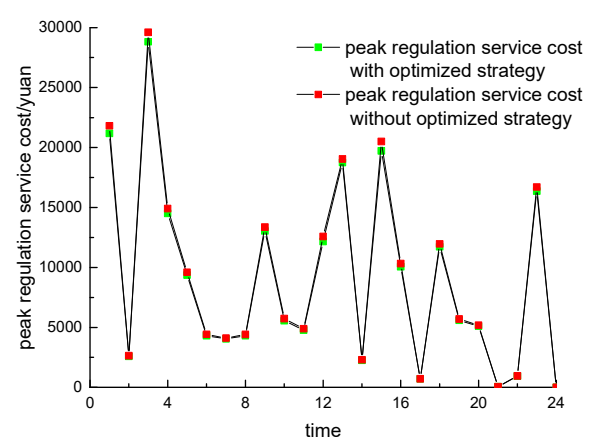

Figure 5. Market peak regulation costs

Figure (6) shows VPP A made internal units output adjustment by considering all income. Since the income in the peak regulation market is higher, the outputs of two CHP units in most periods is lower than the paid peak regulation line, and CHP1 whose total capacity is higher provides more space for peak regulation, but CHP2's depth of peak regulation is deeper.

As shown in figure (7), when generators work together in VPP, VPP can coordinated the output of the internal participants to make the best strategy, so VPP's net revenue is much higher than all units' net revenue sum when separately participating in the market, and after VPP actively involved in peak regulating market, consumption of wind power is improved obviously. 


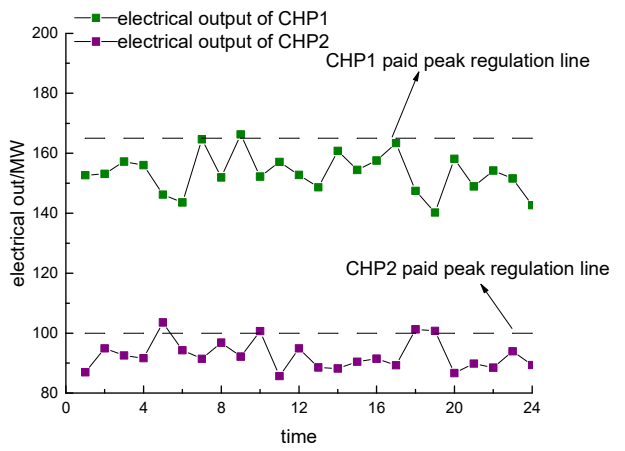

Figure 6. Outputs of CHP units in VPP A after internal adjustment

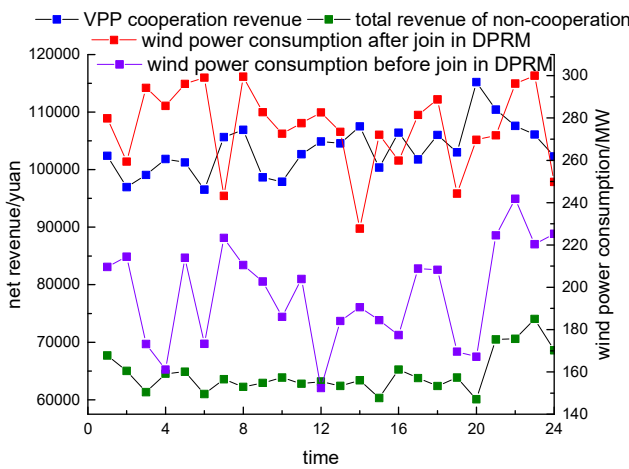

Figure 7. Revenue and consumption of wind power of VPP A

The results of using the Shapley method and the improved method to apportionment the profits are shown in table 5, if only distributing the unit peak regulation income by the marginal contribution, due to CHP1 unit with high capacity and low coal consumption has more peak adjustment, its income is also larger, but after considering historical contributions and peak depth coefficient, since CHP2 tried its best to participate in the peak regulation, so even though the contribution of peak adjustment of CHP2 is less than that of CHP1, the benefit obtained by using the improved apportion method is higher than that obtained by the Shapley value method.

Table 5. Units revenue

\begin{tabular}{|c|c|c|}
\hline method & $\begin{array}{c}\text { CHP1net } \\
\text { revenue(yuan) }\end{array}$ & $\begin{array}{c}\text { CHP2net } \\
\text { revenue(yuan) }\end{array}$ \\
\hline $\begin{array}{c}\text { Shapley value } \\
\text { method }\end{array}$ & $1.3179 * 10^{7}$ & $1.1058^{*} 10^{7}$ \\
\hline $\begin{array}{c}\text { improved } \\
\text { apportion } \\
\text { method }\end{array}$ & $1.2547 * 10^{7}$ & $1.169 * 10^{7}$ \\
\hline
\end{tabular}

\section{Conclusion}

This paper studied the problem of bidding strategy of VPP in deep peak regulation market, and established a twostage bidding model considering multiple uncertainties. Through the simulation results, the following conclusions can be drawn:

(1) VPP with multiple flexible energy resources can achieve higher revenue. By predicting competitor's bidding strategy and pre-clearing, VPP can obtain better bidding strategy. And by adopting this optimized bidding strategy, VPP can obtain higher operating revenue.

(2) When Shapley apportion method is used to distribute revenue, units with larger capacity and lower coal consumption cost can obtain higher revenue, but the improved apportion method can distribute higher revenue to units with deeper realization degree of peak regulation, so as to stimulate thermal power units to deep peak regulation and solve the problem of "wind and heat conflict".

\section{References}

1. Northeast Regulatory Bureau, National Energy Administration. Northeast Electric Power Auxiliary Service Market Operating Rules (Interim) [Z].Shenyang,2019.

2. Northeast Regulatory Bureau, National Energy Administration. Annual Report on the Work of the Government Website in 2019.[EB/OL].http://dbj.nea.gov.cn/ndbg/202001/ t20200119_3726372.html.

3. AlGablawy Mostafa.(2020) Optimal peak shifting of a domestic load connected to utility grid using storage battery based on deep Q-learning network[J]. International Journal of Energy Research, 45(2):3269-3287.

4. Zhao Jinquan, Yang Yuhua, Sun Zhonghao, Ye Hongbo, Ling Xiaobo, Wang Xiaotian.(2020) Deep Peak Regulation Market Mechanism and Clearing Model Considering Participation of Virtual Power Plants.[J]Journal of Global Energy Interconnection, 3(05):469-476.

5. Wang,S.,Lou,S.,Wu,Y.,Cao,K.,Zhou,Y.(2020) Robust Optimal Dispatch of Large-scale Wind Power Integration Considering Deep Peak Regulation Cost of Thermal Power Units [J]. Automation of Electric Power Systems,44(01):118-125.

6. Lin,L.,Yue,X.,Xu,B.,Sun,Y.,Wei,M.(2021)

Sequence and Strategy of Pumped Storage-thermal Combined Peak Shaving ConsideringBenefits of Pumped Storage and Deep Regulation of Thermal Power [J]. Power System Technology,45(01):2032.

7. Cui,Y.,Zhou,H., Zhong,W., Zhao,Y.,Cui,C(2021). Optimal Dispatch of Power System with Energy Storage Considering Deep Peak Regulation Initiative of Thermal Power and Demand Responce [J/OL]. High Voltage Engineering:1-12.

8. Che,Q.,Lou,S.,Wu,T.,Zhang,X.,Wang,X.(2019)O ptimal Scheduling of a Multi-Energy Power System with Multiple Flexible Resources and Large-Scale Wind Power[J]. Energies ,12(18).

9. Luo,Y.,Qiu,S.(2021)A Wind Power Consumption Model of CHP With Thermal Energy Storage Based on Demand Responce[J]. Acta Energiae Solaris Sinica,42(02):90-96. 
10. Dong,H.,Fang,L.,Ding,K.,Wang,N.,Zhang,Z.(201 9)Peak regulation strategy of CSP plants based on operation mode of cogeneration [J]. Acta Energiae Solaris Sinica,40(10):2763-2772

11. Zhou,Y,Hu,W.,Min,Y.,Gao,K.,Jin,X.(2019)Peak Regulation Compensation Price Decision for Combined Heat and Power Unit and Profit Allocation Method [J].Proceedings of the CSEE,39(18):5325-5335+5579.

12. Cao,L., Pan,T., Si,H., Jiang,T., Cao,X.,Zhao,J.(2020) Determination of the Optimal Capacity of Peaking Electric Boiler in CHP Unit[J].Electric Power,53(06):140-146.

13. Su,W.,Wang,J.,Roh,J.(2014)Stochastic energy scheduling in microgrids with intermittent renewable energy resources[J].IEEE Transactions on Smart Grid,5(4): 1876-1883.

14. Rajesh,P.,Prashant,K.,(2019)Economic risk-based bidding strategy for profit maximization of windintegrated day-ahead and real-time doubleauctioned competitive power markets[J].IET Generation Transmission \& Distribution,13(2): 209-218.

15. Liu,P.(2019)Optimal Load Dispatching Based on Tradable Green Certificate[D].North China Electric Power University.

16. Yuan,G.,Jia,X.,Fang,F.,Dong,J.(2020) Joint Stochastic Optimal Scheduling of Heat and Power Considering Source and Load Sides of Virtual Power Plant [J]. Power System Technology,44(08):2932-2940.

17. Lin,L.,Gu,J.,Wang,L.(2019)Optimal Dispatching of Combined Heat-power System Considering Characteristics of Thermal Network and Thermal Comfort Elasticity for Wind Power Accommodation[J]. Power System Technology,43(10):3648-3661.

18. Dai,Y.,Chen,L.,Min,Y.(2017) Optimal Dispatch for Joint Operation of Wind Farm and Combined Heat and Power Plant With Thermal Energy Storage [J].Proceedings of the CSEE,37(12):34703479,3675 .

19. Tian,L.,Xie,Y.,Zhou,G.(2019)Deep Peak Regulation Ancillary Service Bidding Strategy for CHP Units Based on Two-stage Stochastic Programming[J].Power System Technology, 43(8):2789-2798.

20. Ministry of Housing and Urban-Rural Development of the People's Republic of China, Code for design of heating, ventilation and air conditioning for civil buildings[Z].Beijing,2016. 